\title{
ESTUDO DOS CASOS DE CÂNCER BUCAL ATENDIDOS NO PROJETO DE LESÕES BUCAIS DO CESUMAR-MARINGÁ (PR) NO PERÍODO DE 2004 A 2008
}

Priscila Flores ARANTES, Talita Izabela Caliman RODRIGUES, Eduardo MORESCHI

O câncer de boca está entre os 10 cânceres mais freqüentes, apresentando a maior taxa de mortalidade no segmento cabeça e pescoço. Evidências epidemiológicas mostram que a exposição ao sol, tabagismo, alcoolismo, como também ingestão de alimentos pobres em vitaminas, uso de próteses mau ajustadas são fatores de risco desta neoplasia. A incidência do câncer da boca, ainda é um problema de saúde pública em muitas partes do mundo. A situação do tratamento deste tipo de doença é particularmente grave, pois a maioria dos casos geralmente são diagnosticada tardiamente. Este trabalho tem por objetivo fazer um levantamento retrospectivo e de monitoramento dos casos registrados no Projeto de Lesões Bucais do CESUMAR, referentes aos diagnósticos microscópicos das neoplasias da cavidade bucal e estruturas anexas no período de 2004 a 2008. Assim os resultados obtidos através do levantamento de prontuários serão conflitados com os encontrados na literatura para análise dos principais dados referentes a incidências mais freqüentes investigando-se, em paralelo, as variáveis: idade, gênero, raça, localização anatômica, hábitos nocivos e profissão mais acometidos por essa neoplasia.

Palavras-chave: Carcinoma epidermóide; Neoplasia bucal; Mucosa bucal 